\title{
Topographic Distribution of Modality-Specific Amygdalar Neurons in Alert Monkey
}

\author{
H. Nishijo, T. Ono, and H. Nishino \\ Department of Physiology, Faculty of Medicine, Toyama Medical and Pharmaceutical University, Toyama 930-01, Japan
}

Neuronal activity in the amygdala (AM) was recorded from alert monkeys during performance of tasks that led to presentation of rewarding or aversive stimuli. The tasks had 3 phases: (1) discrimination (visual, auditory), (2) operant response (bar pressing), and (3) ingestion (reward) or avoidance (aversion). Neuronal activity was analyzed and compared during each of these phases.

Of 585 AM neurons tested, $312(53.3 \%)$ responded to at least one stimulus in one or more of 5 major groups: vision related, audition related, ingestion related, multimodal, and selective. Forty neurons $(6.8 \%)$ in the anterior dorsolateral capsule of the basolateral nuclei responded exclusively to visual stimuli (vision related). Twenty-six neurons $(4.4 \%)$ further posterior in the basolateral group responded only to auditory stimuli (audition related). During ingestion an additional 41 neurons $(7.0 \%)$ increased their activity (ingestion related). These were in the corticomedial group and at the boundaries between the nuclei of the basolateral group. Of these, 27 responded only in the ingestion phase, 11 during ingestion and at the sight of food, and 3 during ingestion and to certain sounds. Throughout the AM other neurons ( $n$ $=117,20.0 \%$ ) responded to visual, auditory, and somesthetic stimuli and, when tested, to involuntary ingestion of liquid (multimodal). Of these, 40 responded transiently (phasic; 36 exclted, 4 Inhlblted). The remaining 77 maintained their altered activity into the subsequent phases of the task (tonic; 69 excited, 8 inhibited). In each of these 4 categories, most cells were activated primarily by novel or unfamiliar stimuli, and their responses habituated during repeated stimulation. A small number of cells in the basolateral and the basomedial nuclei $(n=14,2.4 \%$ ) were highly selective in that they responded specifically to one biologically significant object or sound more than to any other stimuli (selective). Some of these neurons responded to both sight and ingestion of a specific food. In summary, most AM neurons responded vigorously to novel stimuli, and some of the

\footnotetext{
Received June 7, 1987; revised Nov. 18, 1987; accepted Jan. 22, 1988.

We thank Dr. R. Norgren, Pennsylvania State University, and Dr. A. Simpson, Showa University, for advice and help with the manuscript; Dr. E. Iwai, Tokyo Metropolitan Institute for Neurosciences, for advice on the terminology of the amygdala; and Miss M. Furusaki for typing. This work was supported partly by the Japanese Ministry of Education, Science and Culture Grants-in-Aid for Scientific Research 60440028 and 60216010.

Correspondence should be addressed to Professor Taketoshi Ono, M.D., Ph.D., at the above address.

Copyright (C) 1988 Society for Neuroscience $0270-6474 / 88 / 103556-14 \$ 02.00 / 0$
}

neurons had multimodal responsiveness. These results suggest the AM is related to processing of new environmental stimuli and to those cross-modal association.

Johnston (1923) suggested the amygdala (AM) might function to correlate olfactory, gustatory, and somatic sensory impressions. More recent anatomical and electrical stimulation evidence indicates that the AM receives highly processed information from all sensory modalities via the association cortex (Gloor, 1960; Turner et al., 1980). This evidence has led some investigators to speculate that sensory effects on emotional processes may depend upon relays through the AM (Turner et al., 1980). In addition to a role in emotional processes, the AM had been implicated in a variety of mnemonic processes. In monkey and human, bilateral damage to medial temporal lobes, which include the AM, results in global amnesia, i.e., memory deficits extend to all sensory modalities (Mishkin, 1 882; Zola-Morgan et al., 1982; Murray and Mishkin, 1983; Duyckaerts et al., 1985). It is possible that disconnecting specific sensory input to the medial temporal lobe might result in modality-specific memory deficits (Ross, 1980). In addition, recent lesion studies suggest that the AM is important in cross-modal association (Murray and Mishkin, 1985). All this evidence suggests that sensory processing in the AM contributes to both emotional and mnemonic processes.

Anatomical studies have demonstrated that different sensory systems terminate independently within the AM (Turner et al., 1980). At least within the lateral and basolateral nuclei, some small cells have dendritic fields that are confined to one or another of these limited sensory terminal areas (Millhouse and de Olmos, 1983). In the same areas, larger neurons have extensive dendritic fields (Millhouse and de Olmos, 1983). These studies suggest that these 2 types of neurons might respond preferentially to single or multiple sensory modalitics, respectively. Previous electrophysiological studies reported preferential responses to visual stimulation in the lateral part of the AM in cat (Sawa and Delgado, 1963) and in monkey (Nakano et al., 1987) or in the anterolateral part of the AM in monkey (Sanghera et al., 1979; Ono et al., 1983). Multimodal responses have been reported in the basolateral nuclei in cat (Machne and Segundo, 1956; Ben-Ari et al., 1974) and the central nucleus in rabbit (Kapp et al., 1979).

Although several studies have examined the sensory properties of AM neurons in cat, similar data in the alert monkey remain sparse. In the present study we presented various visual, auditory, somesthetic, and oral sensory stimuli to monkeys while recording from single neurons in the AM. Multimodal respon- 
sive neurons were widely distributed in the AM, while modalityspecific neurons were concentrated in the areas that have been reported to receive modality-specific projections from the temporal lobe (Turner et al., 1980).

\section{Materials and Methods}

Animals and experimental design. Four Macaca fuscata (4-6 kg) were used. The monkeys were restrained painlessly in a stereotaxic apparatus by a previously prepared, surgically fixed head holder designed in our laboratory (Ono et al., 1980, 1981). They sat in a chair facing a panel $24 \mathrm{~cm}$ away that had a window $(10 \times 20 \mathrm{~cm})$ covered by 2 shutters and a bar for operant responding. Liquid was accessible to the monkey through a small spout controlled by an electromagnetic valve (Fig. 1). Aversive stimulation was administered as a weak electric shock $(0.2$ $\mathrm{mA}, 150 \mathrm{~Hz}, 0.3 \mathrm{msec}$ ) applied between the 2 earlobes. The program included feeding, drinking, active avoidance, and auditory discrimination tasks that required the animal to differentiate between stimuli or to relate them to operant bar pressing in order to obtain food or potables or to avoid electric shock.

During recording sessions the animal's behavior and eye movements were monitored by 2 TV cameras or electrooculograms (EOG), or both, as well as the experimenter's observations. The EOG (time constant, $3.2 \mathrm{sec}$ ) were recorded through $\mathrm{Ag}-\mathrm{AgCl}$ electrodes on the lateral edges of the eyes. A color TV camera (WV-3890, National-Panasonic) monitored the panel with its 2 shutters and the animal's bar pressing. A monocolor TV camera (WV-1500, National-Panasonic) monitored the animal's face to record eye movement and mastication. The signals from the $2 \mathrm{TV}$ cameras were synthesized into one picture by a special effects generator (WJ-3000A, National-Panasonic) and recorded on video tape (AG-6300, National-Panasonic) for later analysis. If the monkey exhibited signs of fatigue, such as closing its eyes for several seconds or moving its eyes or hand(s) slowly, the experimental session was stopped immediately. Usually, a unit recording experiment was terminated within 3-4 $\mathrm{hr}$.

Feeding lask. The experimental paradigm has been described previously (Ono et al., 1980, 1981). Briefly, at random intervals, an opaque shutter (W1) was opened so that the monkey could see an object on a turntable through a transparent shutter (W2). The object was either food (raisin, cookie, piece of fruit, etc.) or nonfood (syringe, tape, etc.), and the animal had to press the bar a predetermined number of times (fixed ratio, FR 10-30) to obtain a desired object. The transparent shutter was opened automatically by the last bar press, and the animal could then extend its arm, take the food, and ingest it (Fig. 1B). The task was divided into 3 phases: (1) visual discrimination of food from nonfood (visual); (2) operant responding (bar pressing); and (3) ingestion (oral sensory). Because it was deprived of food and water for $12 \mathrm{hr}$ prior to each session, the monkey normally completed a FR schedule for food or liquid promptly but seldom pressed the bar in nonfood trials. If there was no behavioral or neuronal response, the trial was terminated after $8 \mathrm{sec}$.

Drinking task. In this task, a white or red cylinder indicated a reward: white for juice and red for water. If the animal saw one of these cylinders through W2 after the opening of W1 and met the FR schedule criterion, it could obtain a drop of juice or water. The last bar press automatically closed $\mathrm{W} 1$ and simultaneously opened the electromagnetic valve to deliver a drop of liquid (Fig. 1C).

Active avoidance task. Usually 1 of 2 objects, a brown cylinder associated with electric shock, or a roll of tape that was not associated with electric shock was presented along with a $1200 \mathrm{~Hz}$ tone $(85 \mathrm{~dB})$ in avoidance-related situations. If the animal saw the brown cylinder after the opening of $\mathrm{W} 1$ and heard the $1200 \mathrm{~Hz}$ tone, it had to complete a FR schedule within 4-6 sec to avoid electric shock (Fig. 1D). If the test criterion was met, the last bar press closed W1 and turned off the sound; if not, the tone ceased at the end of the predetermined time and a $1.0 \mathrm{sec}$ shock was applied. W1 was closed at the end of the shock. The electric shock was a train of capacitor-coupled square pulses $(0.2$ $\mathrm{mA}, 150 \mathrm{~Hz}, 0.3 \mathrm{msec}$ ). If the animal saw the tape, it was not necessary to press the bar to avoid electric shock, and it usually did not press the bar in trials with tape plus tone. If the animal pressed the bar when the tape and tone were presented in training and experimental sessions, W1 remained open and the $1200 \mathrm{~Hz}$ tone continued until the bar pressing stopped for at least $1 \mathrm{sec}$. In order to sustain the avoidance reaction to the brown cylinder, shock was applied once or twice before each ex- perimental session by shortening the time required for completion of the FR response to avoid shock.

Auditory discrimination task. In this task, 2 sounds were synthesized in a microcomputer: one, a buzzer noise at $85 \mathrm{~dB}$, was associated with food (cookie or raisin), and the other with a fundamental frequency of $800 \mathrm{~Hz}$ at $85 \mathrm{~dB}$ was associated with juice. When the animal heard one of these sounds, it had to complete a FR schedule to obtain the corresponding food or juice, as in the feeding task. The last bar press automatically turned off the sound, and depending on which sound was presented, either $\mathrm{W} 1$ and $\mathrm{W} 2$ opened simultaneously so the animal could take and ingest a food from the turntablc, or the electromagnetic valve opened to deliver a drop of juice (Fig. $1 E$ ). Two pure tones (2800 or $4300 \mathrm{~Hz}, 85 \mathrm{~dB}$ ) not associated with reward or punishment were introduced as neutral stimuli. In this task, a series of 3 or 4 successive trials of each sound were presented at random.

Combination of each sensory stimuli. When a neuron was isolated, feeding, drinking, avoidance, or auditory discrimination tasks were selected at random and presented in bouts of 3-4 trials each using familiar visual, auditory, and oral sensory stimuli. These trials were followed by somesthetic stimuli such as pricking with a pencil (prick), touching by experimenter's hand (touch), and blowing air on the animal's back (blow). Next, unfamiliar visual, auditory, and oral sensory stimuli were introduced. Unfamiliar visual and oral sensory stimuli were introduced in feeding task situation. Unfamiliar auditory stimuli were presented to calm animals as in auditory discrimination situation. Familiar visual stimuli consisted of 20 kinds of food and nonfood objects that had been used in training sessions. Unfamiliar objects were chosen randomly from a pool of objects and food that were not normally used in the experiments. For auditory stimuli, various complex familiar and unfamiliar sounds such as clicks and those made when the experimenter intentionally rustled a cellophane bag while removing cookies to be placed on the turntable or by a wrench dropped on the floor, for example, were introduced besides familiar cue tones used in auditory discrimination task. Previous studies reported that the complex auditory stimuli were the most effective (Sawa and Delgado, 1963; O'Keefe and Bouma, 1969; Jacobs and McGinty, 1972). Intensities of the controlled complex sounds made by the experimenters ranged from 75 to $90 \mathrm{~dB}$. Uncontrolled environmental sounds, such as switching noise or rustling of a cookie bag, had relatively low intensities of 50-70 dB. Usually somesthetic and auditory stimuli were delivered outside the animal's visual field. Finally, additional familiar and unfamiliar stimuli were tested, again in random order, to confirm the responsiveness of the neuron. These included a light flash, clicks, some somesthetic stimuli, forcible injection of saline, juice, or water into the animal's mouth, and salty food. In forcible injection, each liquid was introduced into the mouth through the same spout as used in drinking and auditory discrimination task. Each neuron was tested with all 4 modalities (visual, auditory, oral, and somesthetic stimuli).

Training and surgery. Animals were first trained in the feeding task to discriminate food or nonfood, after which they readily learned the other tasks. After a monkey learned to perform all tasks to a criterion of $>90 \%$ correct (3-5 weeks), a head-restraining device was attached to the skull under aseptic conditions using sodium pentobarbital anesthesia ( $35 \mathrm{mg} / \mathrm{kg}$, i.m.). Heart and respiratory functions were monitored on an oscilloscope and with an audiomonitor. Rectal temperature during anesthesia was controlled at $37 \pm 0.3^{\circ} \mathrm{C}$ by a blanket heater. The head-restraining device was a $U$-shaped aluminum plate anchored with dental acrylic to stainless steel bolts inserted in keyhole slots in the skull. Antibiotics were administered topically and systemically for 1-2 weeks to protect against infection. After surgery, performance criteria were again attained in $1-5 \mathrm{~d}$ of retraining.

Recording and data analysis. Glass-covered tungsten microelectrodes were stereotaxically inserted stepwise by a pulse motor-driven manipulator (SM-21, Narishige) into various parts of the AM using a chronic stereotaxic apparatus developed in our laboratory (Ono et al., 1980, 1981). Extracellular activity was passed through a high input impedance preamplifier made of a dual-channel field-effect transistor (2SK18A, Toshiba Electric), amplified by a main amplifier, monitored on an oscilloscope, and recorded on magnetic tape (DFR-3715, Sony Magnescale). Neuronal activity was processed in a window discriminator. The spike frequencies were computed over $5.12,12.8,25.6$, or $38.4 \mathrm{sec}$ intervals and displayed as peristimulus time histograms with 128 bins of $40,100,200$, or $300 \mathrm{msec}$, respectively, by an on-line minicomputer (ATAC-450, Nihon Kohden). Another computer (PDP 11/34, DEC) stored the events and times of the trigger signals, spikes, and bar presses for display of rasters and histograms off line. 
A

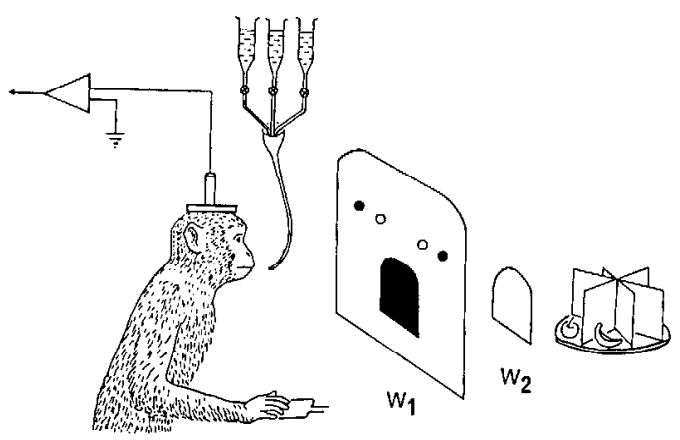

B. FEEDING

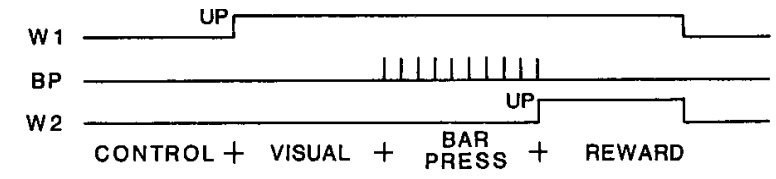

C. DRINKING

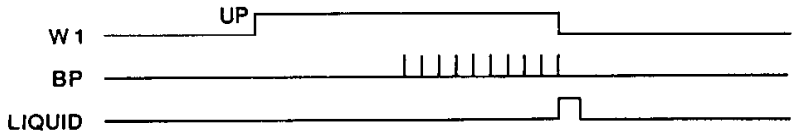

D. AVOIDANCE

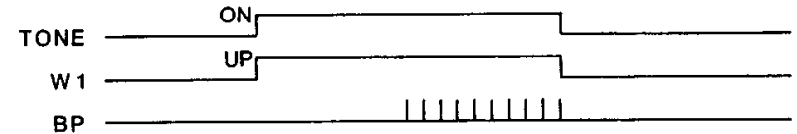

E. AUDITORY DISCRIMINATION

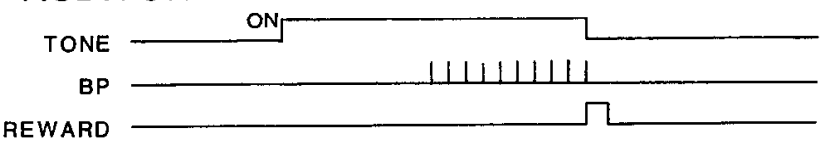

Figure 1. Schema of the experimental set-up and paradigm. A, Monkey sat in a chair facing a panel with a bar and window covered by 2 shutters (W1 and W2). Liquid was provided from small spout. Weak electric shock was driven between the 2 earlobes. $B-E$, Time sequences of feeding, drinking, avoidance, and auditory discrimination tasks. WI, Opaque shutter in front of turntable which opened at $U P(B-D) . B P$, Indications of individual bar presses and time during which they occurred $(B-E)$. Liquid, Dispensed from spout after last bar press $(C)$. Tone, The tone either warned of imminent application of shock if avoidance criterion not met $(D)$ or indicated the availability of reward in the auditory discrimination test $(E)$. Reward, A drop of juice was dispensed from spout after last bar press, or a cookie or raisin became available on the turntable by simultaneous opening of W1 and W2 after last bar press.

Since it has been reported that the spontaneous firing rate of some AM neurons changes over long periods of time after stimulus presentation (Ben-Ari and La Salle, 1972), spontaneous firing rate was checked between and after all trials. Certain unfamiliar stimuli (e.g., gorilla mask) evoked very strong behavioral and neuronal responses followed by a long-lasting increment in spontaneous activity. In such cases, experiments were stopped for at least $10 \mathrm{~min}$ and resumed only if firing returned to essentially the pretrial rates.

As in our previous reports (Nakamura and Ono, 1986; Ono et al., 1986), excitatory or inhibitory responses were defined by analysis of variance (ANOVA, $p<0.01$ ) between spontaneous activity in the pretrial control phase and activity in the first $5 \mathrm{sec}$ after presenting visual (W1 open) or $0.5 \mathrm{sec}$ after presenting auditory stimuli. Comparisons between responses were made by ANOVA between activities in the first $5 \mathrm{sec}$ during visual, or $0.5 \mathrm{sec}$ during auditory, stimulation. Oral sensory responses in the ingestion phase were determined by ANOVA between spontaneous activity in the pretrial control phase and that during 16 sec after food ingestion or $6 \mathrm{sec}$ after water, juice, or saline ingestion. The few responses $(n=8)$ that contained both increases and decreases in firing rate were evaluated by visual inspection of the peristimulus time histograms. This method has been used by others (Richardson and Thompson, 1984). To analyze the tendency for habituation, response magnitude was defined as the average in the first $5 \mathrm{sec}$ after presenting visual or $0.5 \mathrm{sec}$ after presenting auditory stimuli for 3 or 4 trials with any one stimulus, and response magnitude in the first trial was compared, usually, with those in the third and/or fourth trials. Response latency was measured in the feeding, drinking, avoidance, and auditory discrimination tests. Latency and spontaneous firing rates were compared by 2 -tailed Student's $t$ test, with significance levels at $p<0.01$.

Histology and terminology. Near the end of the last experimental session, 8 small marking lesions were made around the AM in each hemisphere by passing 20-30 $\mu \mathrm{A}$ of anodal current for $50 \mathrm{sec}$ through electrodes placed stereotaxically and monitored by X-ray. After all experiments, the animals were deeply anesthetized with overdoses of sodium pentobarbital $(50 \mathrm{mg} / \mathrm{kg})$ and perfused transcardially with $0.9 \%$ saline followed by $10 \%$ buffered formalin. The brains were removed and cut into $100 \mu \mathrm{m}$ sections through the AM. Sections were stained with cresyl violet, and sites of electrical lesions were determined microscopically. The location of each recording site was then calculated from the stereotaxic coordinates of the recording electrode and the coordinates of the marking electrodes. The positions of the AM and of the recording electrodes were checked by X-ray photography (Aggleton and Passingham, 1981) during the experiments, and these photographs were compared with those of the marking electrodes to verify the calculated recording sites.

There have been some variations in terminology of the intra-amygdaloid nuclei. We adopted the atlas of Kusama and Mabuchi (1970) for Macaca fuscata based on Johnston's classification (1923). According to this atlas, the AM is divided into 2 groups: one is the basolateral group, which includes the lateral $(\mathrm{AL})$, basolateral $(\mathrm{ABI})$, and basomedial $(\mathrm{ABm})$ nuclei of the AM; and the other is the corticomedial (CM) group, which includes the central, medial, and cortical nuclei and the anterior amygdaloid area. The lateral, basolateral, and basomedial nuclei in the atlas correspond, respectively, to the lateral, basal, and basal accessory nuclei in the terminology adopted by Price (1981), Turner et al. (1980), and Aggleton and Mishkin (1984) based on the nuclear classification by Crosby and Humphrey (1941).

\section{Results}

Of 585 AM neurons tested in 4 tasks and through 4 modalities, $312(53.3 \%)$ responded in some phase(s) of the operant tasks. Based on their responsiveness to sensory modalities, 238 of these 312 neurons fell into 5 categories - vision related, audition related, ingestion related, multimodal, and selective (Table 1). The multimodal category included neurons that responded to visual, auditory, and somesthetic stimuli, as well as, when tested, to involuntary ingestion of liquid. The selective neurons responded to repeated presentation of only one item. Some cells in this group initially responded very slightly to other stimuli, but these responses habituated within 2-3 trials. The remaining 74 neurons could not be classified. Data from 53 of the 74 unclassified neurons were discarded because their spontaneous activity did not meet the stability criterion. Some of these 53 neurons might otherwise have been classified except that their posttest activity was significantly higher than their pretest activity. This continual increase in activity has been reported previously (Ben-Ari and La Salle, 1972).

\section{Vision-related neurons}

Forty neurons $(6.8 \%)$ responded (all excited) to visual stimuli but not to auditory, oral sensory, or somesthetic stimuli. These 40 neurons responded strongly to unfamiliar objects, habituated to certain objects in repeated trials, and barely responded to familiar neutral stimuli that were not associated with reward or aversion. Those neurons responded to virtually every unfamiliar object regardless of whether or not it was food. The response 
Table 1. Classification, spontaneous firing rate, latency, and number of cach AM neuron type

\begin{tabular}{|c|c|c|c|c|c|}
\hline \multirow[b]{2}{*}{ Classification } & \multirow{2}{*}{$\begin{array}{l}\text { Spontaneous } \\
\text { firing rate } \\
\text { (spikes/sec) }\end{array}$} & \multirow[b]{2}{*}{ Latency (msec) } & \multicolumn{3}{|c|}{ No. of neurons } \\
\hline & & & $\overline{\mathbf{E}}$ & $\mathrm{I}$ & Total $^{a}$ \\
\hline Vision & $3.65 \pm 3.25$ & $203.3 \pm 27.1$ & 40 & 0 & $40(6.8)$ \\
\hline Audition & $4.03 \pm 2.63$ & $78.1 \pm 13.8$ & 26 & 0 & $26(4.4)$ \\
\hline \multicolumn{6}{|l|}{ Ingestion } \\
\hline Oral & $4.04 \pm 3.18$ & $\mathrm{ND}^{b}$ & 27 & 0 & $41(7.0)$ \\
\hline Oral + vision & $0.59 \pm 0.50$ & $255.7 \pm 37.8$ & 11 & 0 & \\
\hline Oral + audition & $0.37 \pm 0.27$ & $\mathrm{ND}^{c}$ & 3 & 0 & \\
\hline \multicolumn{6}{|l|}{ Multimodal } \\
\hline Phasic & $5.85 \pm 4.91$ & $131.5 \pm 71.8$ & 36 & 4 & $117(20.0)$ \\
\hline Tonic & $7.32 \pm 9.08$ & $168.1 \pm 55.0$ & 69 & 8 & \\
\hline Sclective & $0.31 \pm 0.27$ & $233.3 \perp 44.4$ & 14 & 0 & $14(2.4)$ \\
\hline \multicolumn{6}{|l|}{ Unclassified } \\
\hline Uncertain responses & & & & & $21(3.6)$ \\
\hline Variable baselines & & & & & $53(9.1)$ \\
\hline No response & & & & & $273(46.7)$ \\
\hline Total & & & & & $585(100)$ \\
\hline
\end{tabular}

E, excitation; I, inhibition.

a Percentage given in parentheses.

${ }^{b}$ Not determined because of the lack of sensitivity to visual and auditory stimuli.

c Not determined because of complexity of stimulus and weak sound.

magnitudes to unfamiliar objects were greater than at least some familiar food and nonfood objects.

An example of vision-related neurons that responded only to visual stimuli is shown in Figure 2, which shows responses to various visual stimuli $(A-F)$, and strong responses to unfamiliar visual stimuli (dried yam, small bottle), as compared with the responses to the familiar cookie $(A)$ and white cylinder associated with juice $(B)$. In contrast, this neuron did not respond to familiar auditory $(G-I)$ or somesthetic $(J)$ stimuli. However, these stimuli did elicit various overt reactions (but not bar pressing). Figure 2, $A, C$, shows no response to food put into the animal's mouth (indicated by arrow), so this neuron did not respond to oral sensory stimuli. Figure $2 E$ shows responses in what would have been the ingestion phase, but in this case the monkey handled and looked at the food without putting it into its mouth, so there was no actual ingestion phase. Non-visual stimuli did not elicit responses from the neuron, and visual responses habituated rapidly (Fig. 3 ). In trials $1-4$ the response to a pink plastic rectangular parallelepiped habituated when the long axis was horizontal, but responses to the same object reappeared when the form was reoriented with the long axis vertical (trial 5) and then habituated again (trials 6-8). This neuron did not respond to somesthetic (trial 10, prick) or auditory stimulia tone associated with juice (trial 9) or a click (trial 12). This neuron responded strongly, however, to the sight of a familiar glove (trial 11), a familiar aversive object described in detail in the accompanying paper. The spontaneous firing rate and latency of the vision-related neurons ranged from 0.12 to 18.85 $(3.65 \pm 3.25$, mean $\pm \mathrm{SD}, n=35)$ spikes/sec and from 140 to $260(203.3 \pm 27.1, n=35) \mathrm{msec}$, respectively.

\section{Audition-related neurons}

Auditory stimulation elicited responses in 26 neurons (4.4\%). Except for the effective modality, audition-related neurons had characteristics similar to those of vision-related neurons. All of these 26 neurons responded vigorously to unfamiliar sounds and habituated to certain auditory stimuli in repeated trials; none responded to 2 familiar pure tones used as controls. The responsiveness to unfamiliar sounds depended on intensity and unfamiliarity of the sounds but were independent of the frequency. Although there were some differences in time course, these neurons responded and then habituated to virtually every unfamiliar complex sound made by the experimenter. After habituation, the responses temporarily reappeared if the intensity increased.

An example of audition-related neurons is shown in Figure 4. Although the associated rewards were the same, this neuron did not respond to visual stimuli associated with feeding and drinking $(A, B)$, but did respond to cue tones $(D, E)$. This neuron appeared to respond to the brown cylinder associated with electric shock $(C)$, but this response was believed to be related to the $1200 \mathrm{~Hz}$ tone, and not to the sight of the brown cylinder, because it did not respond to any other visual stimuli, including a cookie or the white cylinder. This neuron also responded to clicks $(F)$ and unfamiliar sounds (not shown), but in repeated trials the responses quickly habituated $(F)$. The spontaneous firing rates and latency of these audition-related neurons were $0.11-11.40(4.03 \pm 2.63, n=16)$ spikes/sec and 60-100 (78.1 $\pm 13.8, n=16) \mathrm{msec}$.

\section{Ingestion-related neurons}

There were 41 neurons (7.0\%) that responded primarily during the ingestion phase of the discrimination tasks. Depending on responsiveness to other stimuli, this group was subdivided into 3 groups (Table 1): 27 responded only after a monkey put food into its mouth, after it drank juice or water, or both (oral sensory); 11 responded to the sight of certain food, as well as during ingestion (oral sensory + vision); and 3 responded routinely during ingestion and to the sound that was made when the experimenter rustled the cookie bag outside of the animal's visual field (oral sensory + audition). The spontaneous firing rates of oral sensory neurons were $0.08-12.9(4.04 \pm 3.18, n=$ 


\section{FR:10 N:4}

A

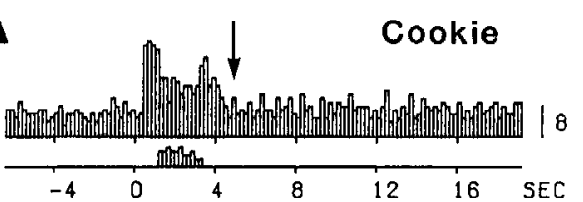

C

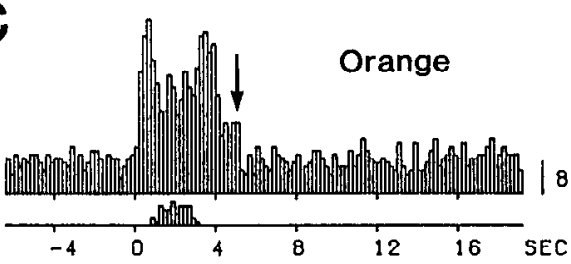

E

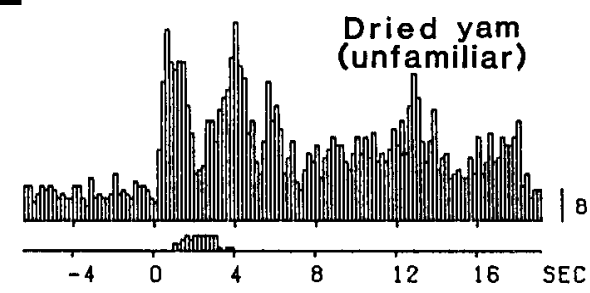

Tone (cookie)

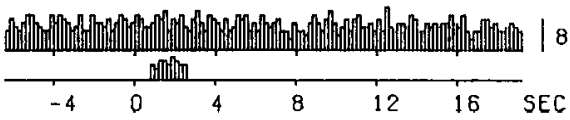

1

Click

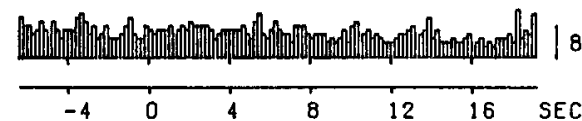

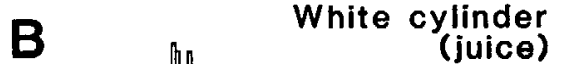

(juice)

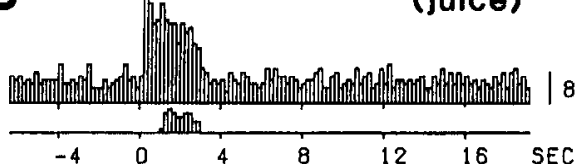

D Brown cylinder

(avoidance)

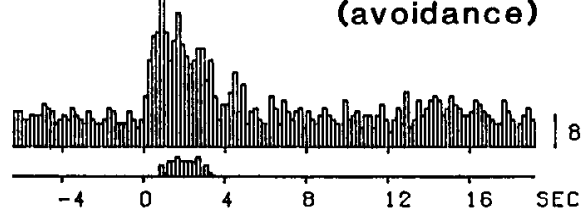

$\mathbf{F}$

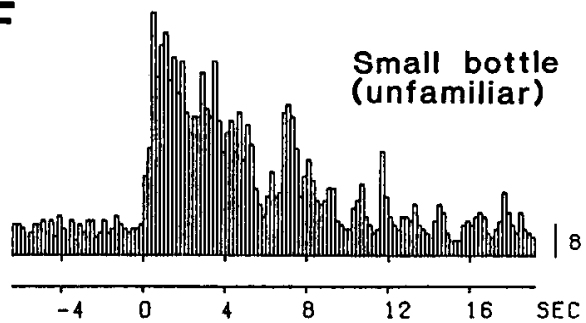

$\mathrm{H}$

Tone (juice)
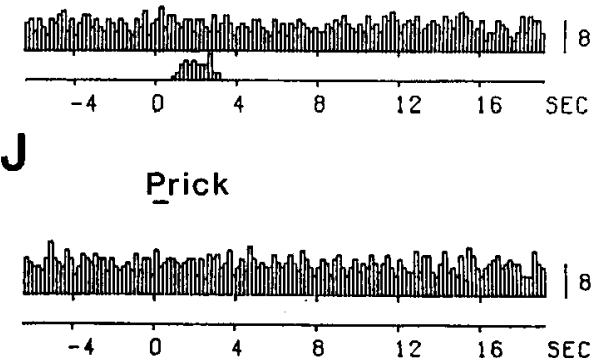

22) spikes/sec. Latency of the oral sensory plus visual responses to the sight of food was 200-310 (255.7 $\pm 37.8, n=7) \mathrm{msec}$ and spontaneous firing rates were 0.11-1.61 $(0.59 \pm 0.50, n=$ 7) spikes/sec.

Figure $5 A$ shows representative data of an oral sensory neuron. This neuron responded only during the ingestion phase of food $(a, b, d-f)$, and juice (c) trials but not in the visual $(a, b, e, f)$ or auditory $(c, d)$ discrimination phases and not to other auditory $(g)$ and somesthetic $(h)$ stimuli. The variation in response latency observed across trials could not be accounted for simply by the physical properties of food ingested; rather, it was correlated with unfamiliarity or palatability. The response latencies to unfamiliar cucumber $(f)$ and preferred watermelon $(e)$ were shorter than those to the less preferred cookie $(a)$ and raisin $(b)$. The shorter latency is evident for other unfamiliar or preferred food (not shown).

As with the auditory neurons, oral sensory neurons had characteristics basically similar to those of vision-related neurons. These neurons responded more strongly to unfamiliar food $(f)$ than to less preferred familiar food $(a, b)$. Further, the response to highly preferred watermelon $(e)$ was stronger than that to less preferred cookie $(a)$ and raisin $(b)$. This tendency was evident for other palatable food (not shown). In some oral sensory neurons, responsiveness to certain kinds of less preferred food (cab- bage, mushroom, cookie, and raisin) exhibited a tendency to habituate. Of the 27 oral sensory neurons, responses of 5 habituated in repeated trials. The characteristics of habituation are shown in Figure $5 \mathrm{~B}$. Although bar pressing and mouth movement did not change, neuronal responses to cabbage habituated in successive trials $1-5$. These results also imply that the response of this neuron was not tightly linked to ingestion-related motor activity.

\section{Multimodal phasic neurons}

During the discrimination phase, various stimuli, regardless of their affective significance, elicited phasic responses in 40 neurons $(6.8 \% ; 36$ excited, 4 inhibited). Responses that peaked in the discrimination phase and returned to the spontaneous level before or very early in the bar press phase were defined as phasic. No transient responses were observed later in the task. Four neurons tested also responded to involuntary ingestion of liquid. Examples of responses of a typical neuron of this type are shown in Figure 6. This neuron responded to reward $(A)$, to known aversive or potentially aversive $(B, C)$, and to neutral stimuli $(D)$, as well as to a light flash $(E)$, although the affective quality of the flash is unknown. This particular neuron was also sensitive to somesthetic $(F)$, and familiar neutral auditory $(G, I I)$ stimuli. The spontaneous firing rates of this type of neuron ranged from 


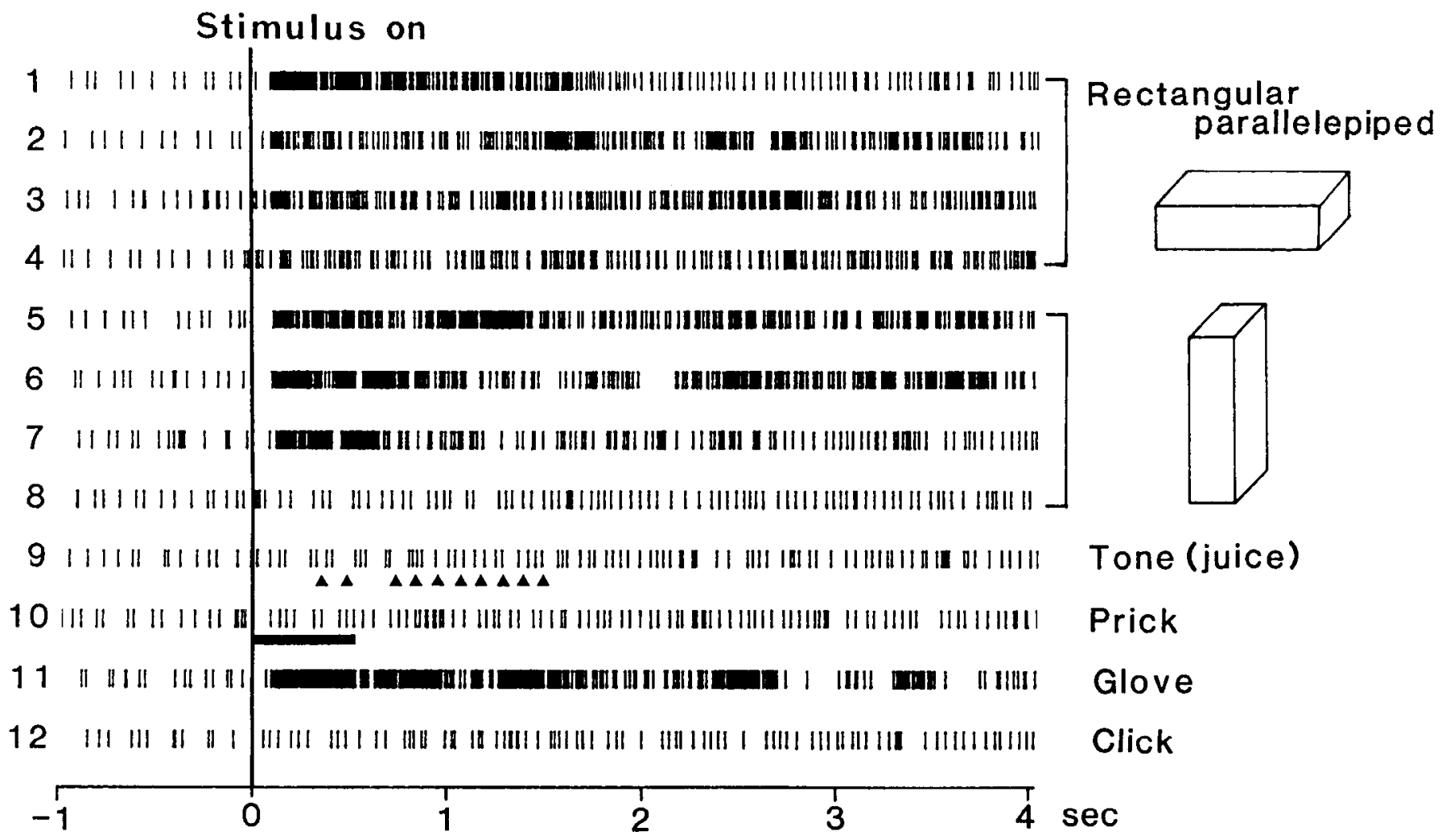

Figure 3. Vision-related neuron responses shown as raster display to sequential presentation of visual, auditory, and somesthetic stimuli. Neuronal response to a pink plastic rectangular parallelepiped in different positions habituated in trials $1-4$ and $5-8$. Neuron did not respond to auditory or somesthetic stimuli in trials 9,10 , and 12 but did to visual stimulus in trial 11. Each filled triangle below a raster display indicates a bar press. Abscissa, time (sec); W1 opened at time 0.

0.22 to $17.90(5.85 \pm 4.91, n=31)$ spikes/sec, and the response latency was $40-390(131.5 \pm 71.8, n=31) \mathrm{msec}$.

\section{Multimodal tonic neurons}

A response was defined as tonic if it persisted through 2 or morc phases of the task (in the FR 10 schedule). Tonic responses to various sensory modalities appeared in 77 neurons $(13.2 \%$; 69 excited, 8 inhibited). Of the 4 modalities tested, vision was usually the most effective and somesthesis, the least. The most effective visual stimuli were usually unfamiliar objects and the least effective were familiar, neutral, nonfood objects such as tape and W1 shutter movement. Typical results from a neuron of this type are shown in Figure 7 . This neuron responded to both visual and auditory cues, during ingestion $(A, B)$, as well as to somesthetic stimuli $(C)$. This neuron also responded strongly to an unfamiliar object $(E)$, but not to a familiar, neutral, nonfood object $(D)$. Responses to a glass pyramid and other unfamiliar objects habituated in several trials (not shown). The spontaneous firing rates of these neurons ranged from 0.11 to 33.76 (7.32 $\pm 9.08, n=64)$ spikes/sec and the latency of these responses was 55-320 (168.1 $\pm 55.0, n=64) \mathrm{msec}$.

\section{Selective neurons}

Fourteen neurons $(2.4 \%)$ that responded to only one stimulus item were placed in this category: 5 responded to a nonfood item, 6 to food, and 3 to a particular sound. Those items that elicited specific responses are listed in Table 2. These neurons were tested with as many items as was practical, usually between 20 and 40 . The ranges and spontaneous firing rates and latency of the selective neurons were $0.10-0.94(0.31 \pm 0.27, n=9)$ spikes/sec and 180-330 (233.3 $\pm 44.4, n=9)$ msec.

The activity of a neuron that selectively responded to watermelon is shown in Figure 8. This neuron was tested with 16 objects and 7 somesthetic and auditory stimuli (not all shown). The magnitude of its response to the sight of watermelon was

Table 2. List of stimuli that elicited selective responses

\begin{tabular}{lll} 
& $\begin{array}{l}\text { No. of responding } \\
\text { neurons }\end{array}$ & Monkey \\
\hline Nonfood & & \\
$\quad$ Glove & 2 & A, C \\
Syringe & 1 & A \\
Spider model & 1 & B \\
Stick & 1 & B \\
Food & & \\
$\quad$ Raisin & 3 & A, B, C \\
Watermelon & 1 & C \\
White cylinder & 1 & A \\
$\quad$ Red cylinder & 1 & B \\
Sound & & \\
$\quad$ Rustling of cookie bag & 1 & C \\
Switching noise & 1 & B \\
$\quad$ Hitting of metal can & 1 & A \\
Total & 14 & \\
\hline
\end{tabular}

A-C: individual monkeys used in present study. No selective responses observed in $\mathrm{D}$ attributed to low probability of spontaneous firing. 

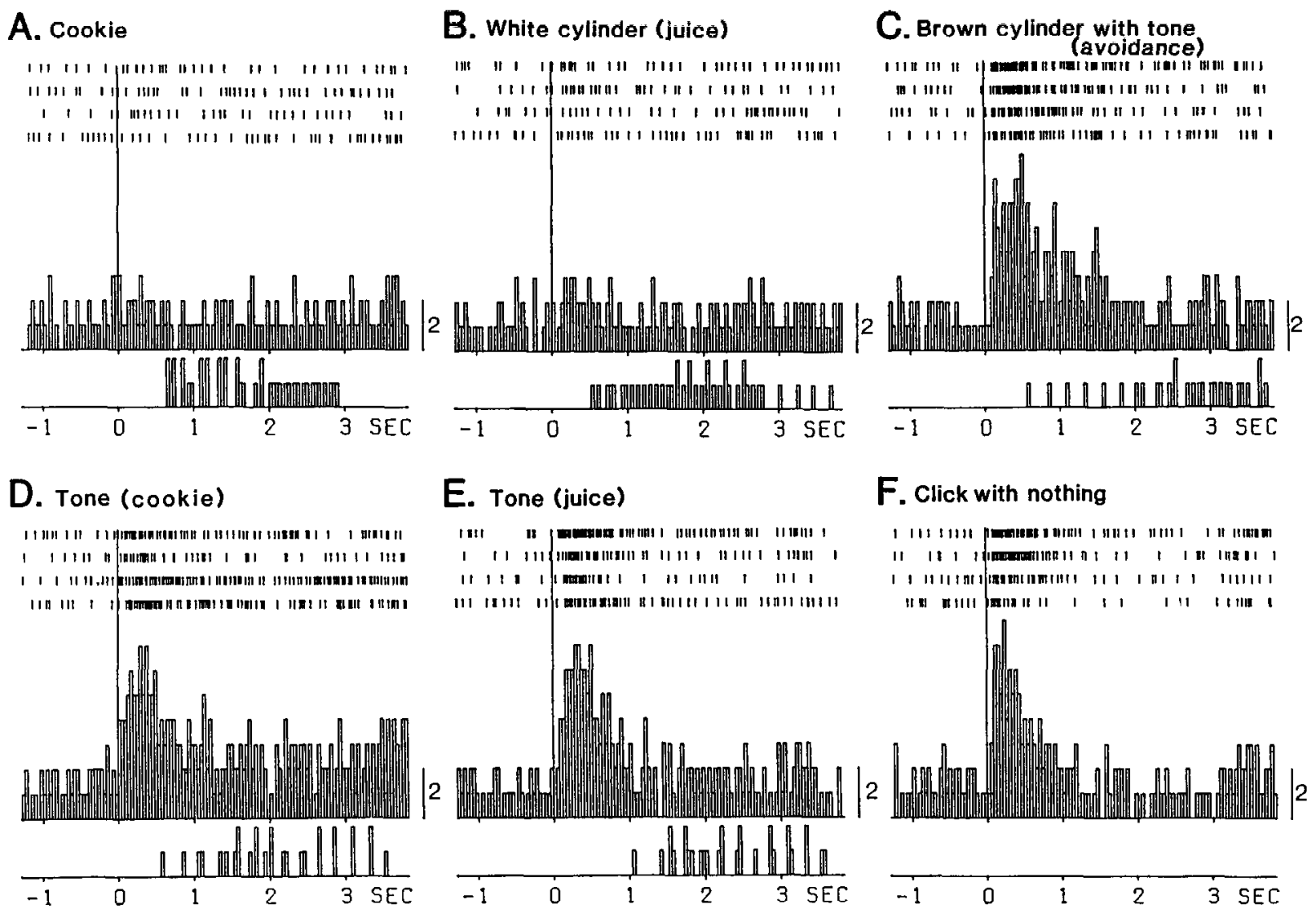

Figure 4. Audition-related neuron responses shown as raster displays and summed histograms (40 msec bins, 5.12 sec) for 4 trials. Neuron responded only to auditory $(D, E)$, but not to visual $(A, B)$ stimuli. Neuron also responded to $1200 \mathrm{~Hz}$ tone used in avoidance task $(C)$ and to auditory stimulus $(F)$. Note rapid habituation of responses to click $(F)$. Other descriptions as for Figure 2.

much greater than to any other stimulus $(A)$. The neuron responded only slightly to the sight of a strawberry model in the first trials only $(A)$, with the responses disappearing in the second and third trials. The neuronal responses to an apple, usually a highly preferred food of monkeys, were similar to those for the strawberry model $(A)$. This neuron also responded to ingestion of watermelon $(B)$. Neurons with selective responses for a specific food item did so only during ingestion of that item.

\section{Unclassified neurons}

This group included 74 neurons (12.7\%) that responded to certain stimuli but, for one reason or another, could not with certainty be placed in any category. Twenty-one of these neurons had relatively long latency responses (more than $350 \mathrm{msec}$ ), some had biphasic responses (initial inhibition followed by excitation), and for some of these latter neurons the amount of inhibition and excitation varied from trial to trial. Only one neuron responded specifically in anomalous situations, such as when reward was withheld or when an incorrect response was made. The spontaneous activity of 53 neurons increased gradually but steadily during testing, so that the posttrial rate was significantly higher than the pretrial rate (ANOVA, $p<0.01$ ). Eleven of these never recovered to the control rate in more than $10 \mathrm{~min}$, and 42 were lost while waiting for recovery.

\section{Recording sites, latency, and spontaneous firing rate}

The recording sites and the excitatory-inhibitory nature of the responses are depicted in Figure $9 A$. Recording sites from both hemispheres of 4 monkeys are plotted on representative sections of the left hemisphere. Of 312 ncurons that responded to some stimuli, $275(88.1 \%)$ were excited (open circles), $29(9.3 \%)$ were inhibited (filled circles), and $8(2.6 \%)$ were inhibited-excited (half-filled circles). Spontaneous unit activity occurred infrequently in the lateral AM, especially in the lateral nucleus, so relatively few neurons were recorded from there. Most responses, especially in the basolateral group, were excitatory.

The distribution of the response latencies of the 182 neurons checked for this parameter (31 multimodal phasic, 64 multimodal tonic, 35 vision related, 16 audition related, 7 oral sensory plus visual, 9 selective and 20 unclassified neurons) is indicated in Figure $9 B$ (open area). The latency of the visionrelated responses (black area) was longer than that of the audition-related responses (hatched area) (2-tailed Student's $t$ test, $p<0.001)$. The oral sensory plus visual and the selective types had extremely low spontaneous firing rates ( $<1$ spike/sec) in contrast to the other types (2-tailed Student's $t$ test, $p<0.01$ ).

\section{Location of each neuron type}

There was no significant difference between the 2 hemispheres nor among the 4 monkeys. Except for oral sensory plus audition and selective neurons, both of which were quite scarce, every response classification was observed in all 4 animals. The distributions of the various neuron types are illustrated in Figure 10. Vision-related neurons were located in the anterior dorsolateral part of the AM, including the lateral and basolateral 
A FR: $10 \mathrm{~N}: 3$

a. Cookie

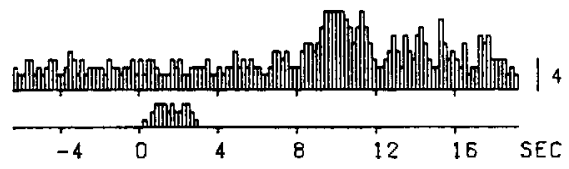

C. Tone (juice)

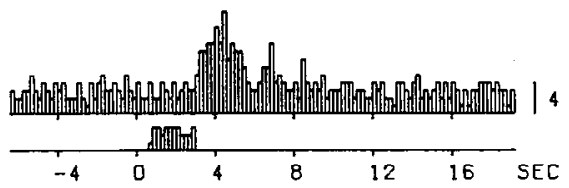

e. Watermelon

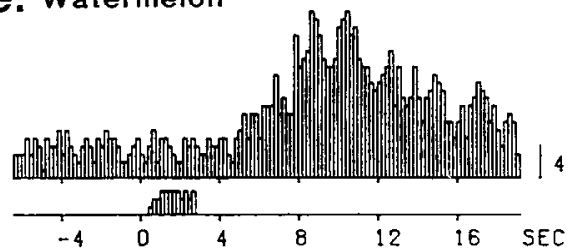

g.

Click

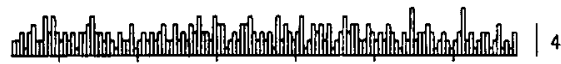

b. Raisin

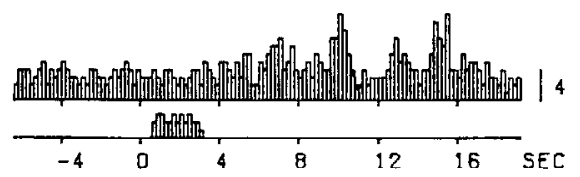

d. Tone (cookie)
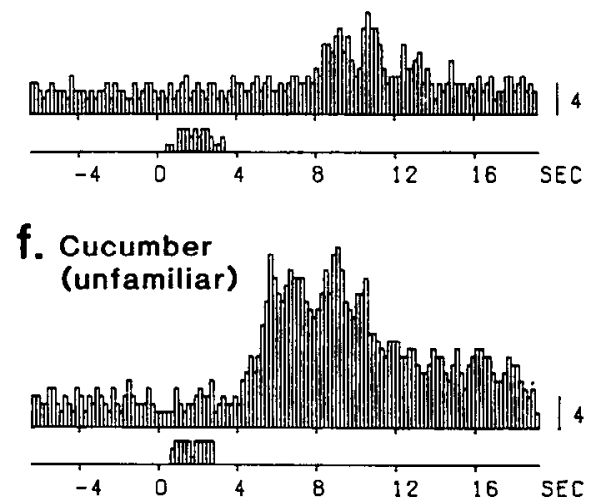

h.

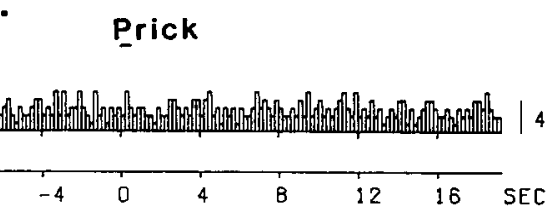

Figure 5. Oral sensory neuron responses shown as histograms $(A)$ and raster display $(B)$. $A$, Activity increased only in ingestion phase $(a-f)$. The neurons did not respond in visual $(a, b, e$, $f)$ or auditory $(c, d)$ discrimination phases, nor to auditory $(g)$ or somesthetic $(h)$ stimuli. Note prominent responses to ingestion of watermelon $(e)$ and unfamiliar cucumber $(f)$. Other descriptions as for Figure 2. $B$, Neuronal responses to sequential trials of cabbage. Note habiluation of responses in ingestion phase. Each arrow below a raster indicates time when animal put food into its mouth. Other descriptions as for Figure 3 . nuclei (Fig. 10A, filled triangles). The audition-related neurons were located more posteriorly in the basolateral group of the AM ( $A$, filled circles). Ingestion-related neurons were located in the middle portion of the AM in the corticomedial group and the medial part of the lateral nucleus or along the border between the lateral and basolateral nuclei, and along the dorsal surface of the basolateral nucleus ( $A$, open squares). The multimodal phasic (Fig. 10B, open circles) and tonic ( $B$, open triangles) neurons were widely distributed in the AM. The selective neurons were located in the basolateral and basomedial nuclei ( $B$, filled squares).

\section{Discussion}

\section{Vision- and audition-related neurons}

Forty neurons responded exclusively to visual stimuli; 26 others, exclusively to auditory stimuli. Previously Sanghera et al. (1979) reported that neurons in the dorsolateral AM responded only to visual stimuli but not to other sensory modalities, although their topographical location in each nuclei was uncertain. They reported that most of the neurons responded differently to different stimuli. Gross topographical location and the characteristics of neuronal responsiveness in their study are similar to those of vision-related neurons in the present study. In the present study, the responses of vision-related neurons tended to habituate, which is consistent with data from our previous study (Ono et al., 1983). Nevertheless, unfamiliar visual stimuli elicited vigorous responses from many of these neurons. Although Sanghera et al. (1979) unfortunately did not test with novel visual stimuli, the lesion studies reported that the AM lesion decreased the orientation to novel visual stimuli in monkey (Bagshaw et al., 1972).

Two previous studies in monkey reported AM neurons that responded to both auditory and visual stimuli (Sanghera et al., 1979; Nakano et al., 1987) or cue tone-related responses (Nakano et al., 1987), but in neither case did neurons respond exclusively to auditory stimuli. In cat AM it was reported that 

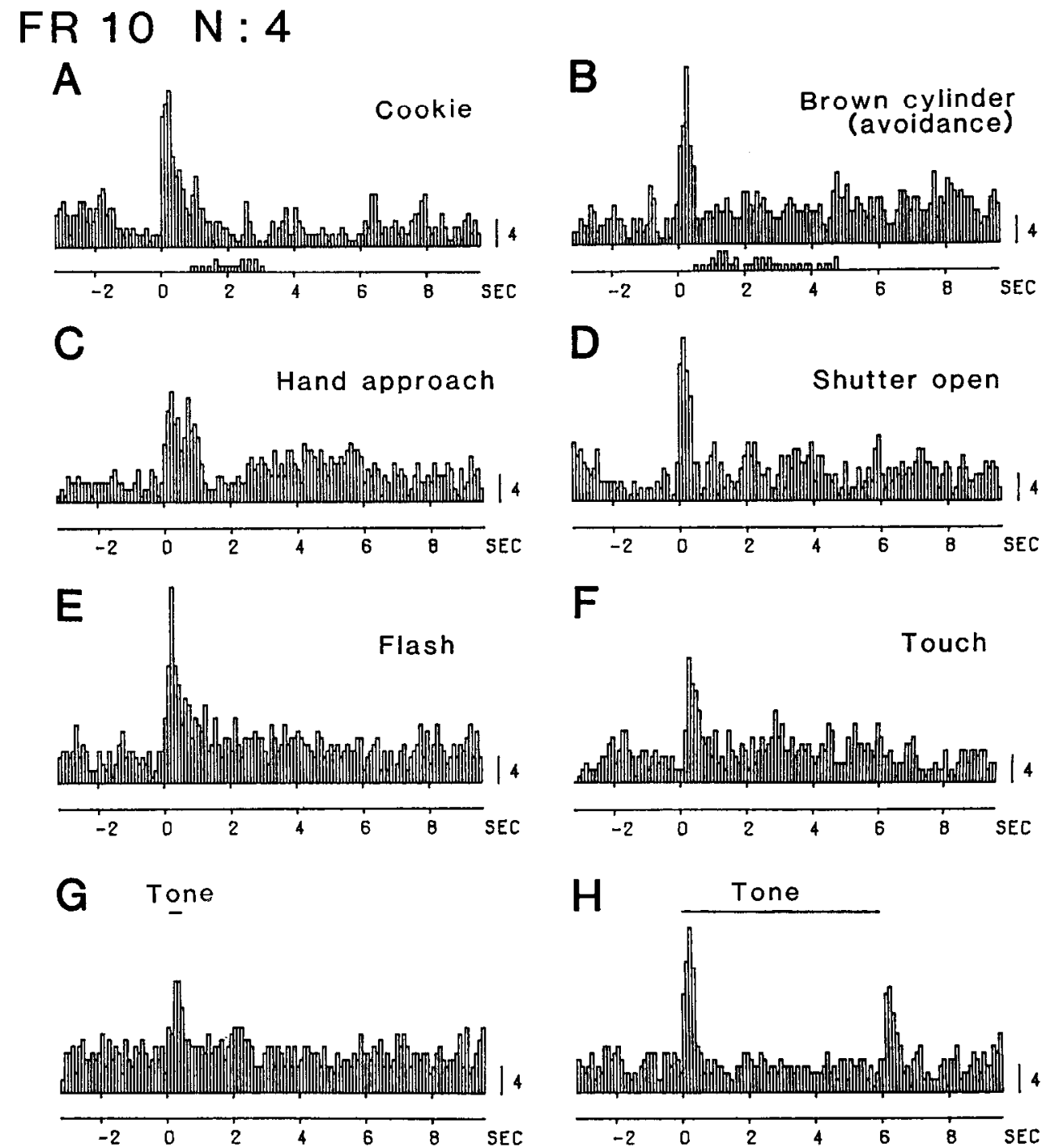

Touch

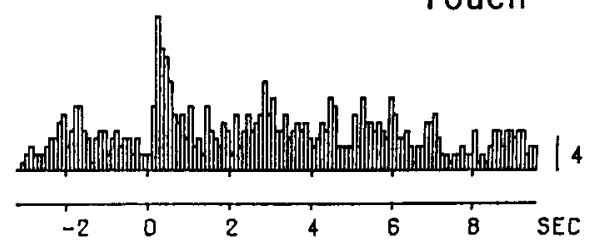

$\mathrm{H}$
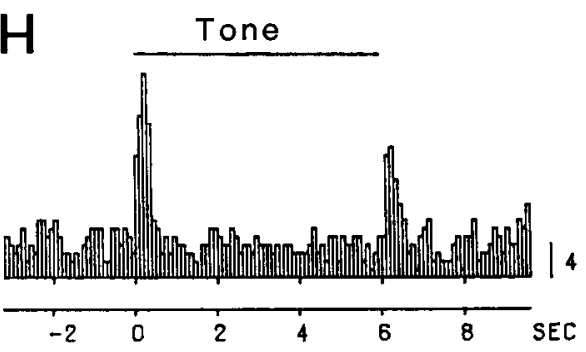

Figure 6. Multimodal phasic neuron responses shown as histograms $(100$ msec bins, $12.8 \mathrm{sec}$ ). Activity increased transiently in response to presentation of positive $(A)$ and negative $(B)$ affection-related objects, to approach of experimenter's hand $(C)$, to shutter opening $(D)$, to light flash $(E)$, to touching monkey's back $(F)$, and to turning tone $(4300 \mathrm{~Hz})$ on and off $(G, H)$. Other descriptions as for Figure 2. auditory stimuli were the most provocative (Sawa and Delgado, 1963; O'Keefe and Bouma, 1969), but some of these responses habituated in repeated trials (Sawa and Delgado, 1963; Ben-Ari and La Salle, 1974). The latter results are consistent with our present results. The predominance of vision-related neurons over audition-related neurons in the present study may be due to the fact that primate is more dependent on visual stimuli, whereas the auditory stimuli are predominant for coding environmentally significant stimuli in cat (Grossman, 1962).

\section{Ingestion-related neurons}

Forty-one neurons responded primarily during the ingestion phase of the task. These neurons probably responded to the intraoral sensory characteristics of the food or fluid, but it is possible that they were influenced by some visceral afferent sequelae of ingestion. We demonstrated previously that responses during ingestion were modulated by state of satiation or by different kinds (taste) of food (Nishijo et al., 1986). In the present experiments, both preferred and unfamiliar food elicited stronger responses than did less preferred food. Texture differences between hard and soft food are not sufficient to explain this result. At least some of the response changes observed could be related to the gustatory factor of food.
The central, lateral, and basolateral nuclei of the AM receive abundant afferent fibers from the insular cortex (Aggleton et al., 1980; Turner et al., 1980), which is reported to receive gustatory inputs in monkey (Turner et al., 1980; Pritchard et al., 1986), mouse (Shipley and Geinisman, 1984), and rat (Yamamoto et al., 1984; Kosar et al., 1986b). Unit recording studies reported that some units in the anterior insular cortex responded to gustatory or oral somatosensory stimuli in monkey (Sudakov et al., 1971; Scott et al., 1986) and rat (Yamamoto et al., 1984; Kosar et al., 1986a). Schwartzbaum and Morse (1978) reported gustatory responses in the central amygdaloid nucleus in rabbit. Most of our ingestion-related neurons were also located in the central nucleus. According to their study, units that responded to a broader spectrum of food tastes had higher spontaneous activity than highly selective units. Our results agree with theirs. In the present study, oral sensory neurons that responded to several foods had significantly higher spontaneous activity than oral sensory plus vision neurons that responded only to some specific foods (2-tailed Student's $t$ test, $p<0.01$ ). Other physiological studies have reported neurons in the central and basolateral nuclei that responded to gustatory stimuli (Schwartzbaum and Morse, 1978; Yamamoto et al., 1981; Nishijo et al., 1986). 


\section{A. Orange}

\section{W1 open}

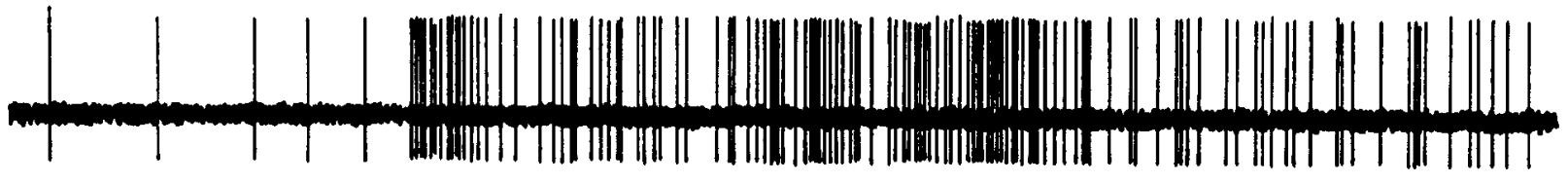

$\Delta$

$\Delta \Delta \Delta \Delta \Delta \Delta \Delta \Delta$

\section{B. Tone (juice) Tone on}

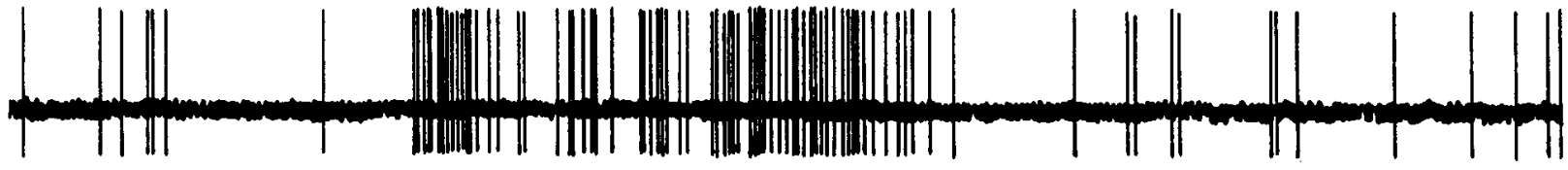

$\Delta$

$\Delta \Delta \Delta \Delta \Delta \Delta \Delta \Delta$

C. Prick

Prick

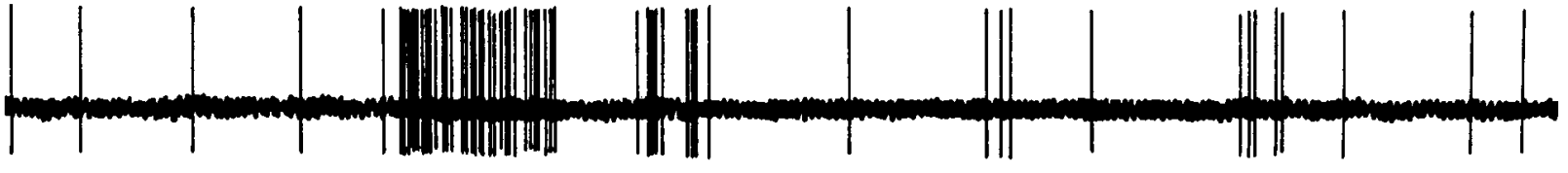

D. Tape

W1 open

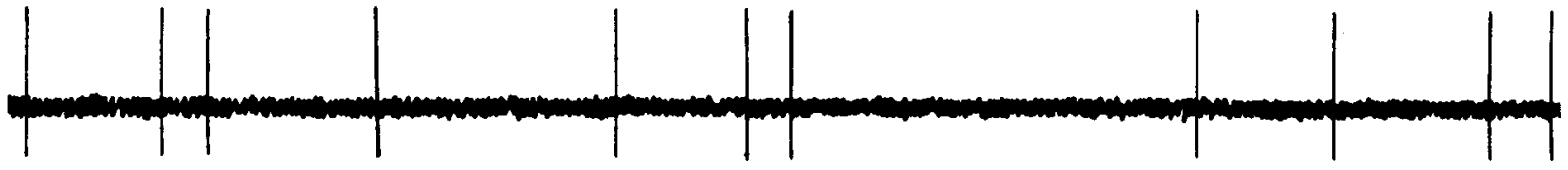

\section{E.Glass pyramid W1 open}

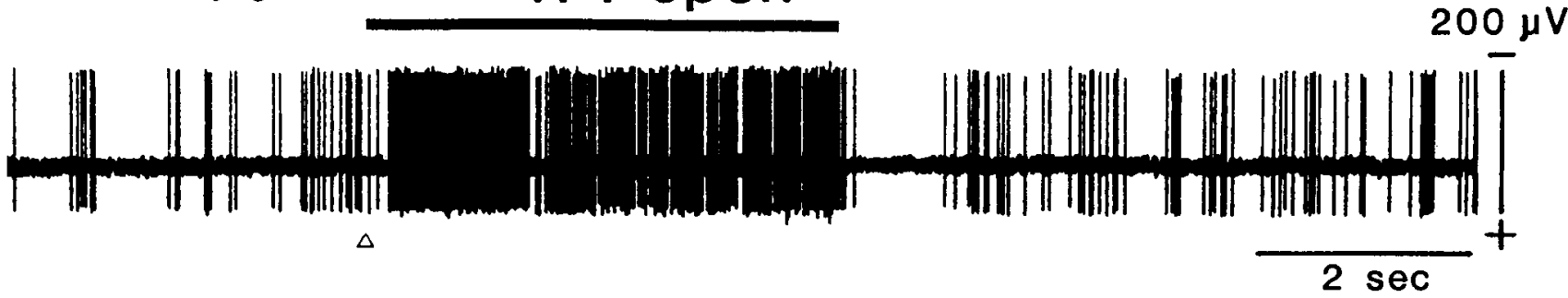

Figure 7. Multimodal tonic neuron responses shown as raw records. The neuron responded at sight and ingestion of orange $(A)$, to tone associated with juice and ingestion of juice $(B)$, and to pricking of animal's back with pencil $(C)$. Neuron did not respond at sight of neutral familiar object $(D)$ but responded strongly at sight of unfamiliar object $(E)$. Each open triangle indicates time of stimuli $(A, D$, and $E$, W1 opening; $B$, onset of cue tone; $C$, onset of pricking). Filled triangles, bar presses; filled circle, placement of food into animal's mouth.

\section{Multimodal neurons}

According to Ben-Ari et al. (1974), inhibitory responses were predominant in cat AM, while in the present and other studies, excitatory responses predominated (Machne and Segundo, 1956;
Creutzfeldt et al., 1963; Sawa and Delgado, 1963). Ben-Ari et al. (1974) also reported that the multimodal responses were abundant in the lateral nucleus, while in the present and other studies (Creutzfeldt et al., 1963), the multimodal responses were rare in the lateral nucleus. Since electrical stimulation of the 


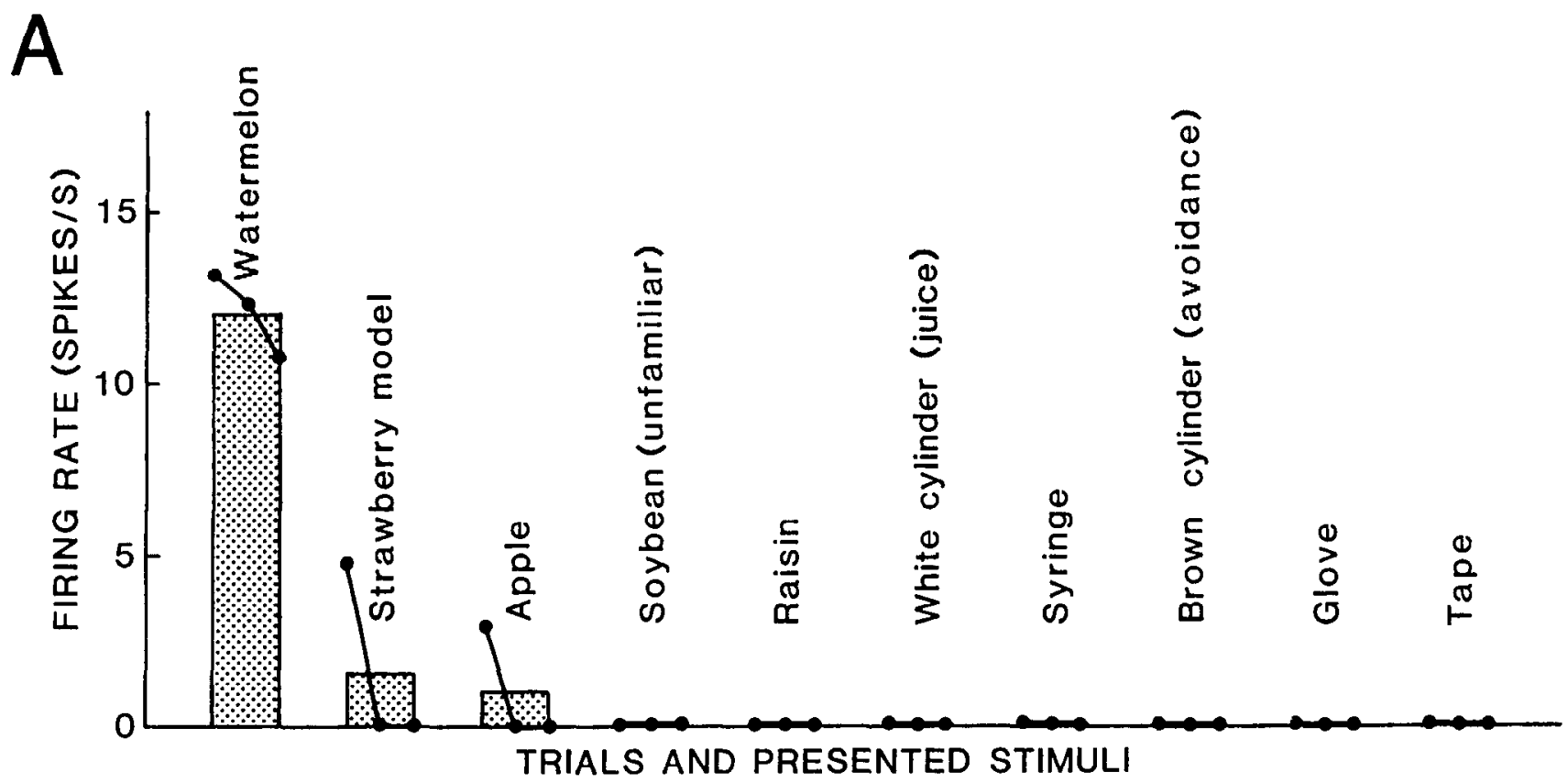

B. WATERMELON

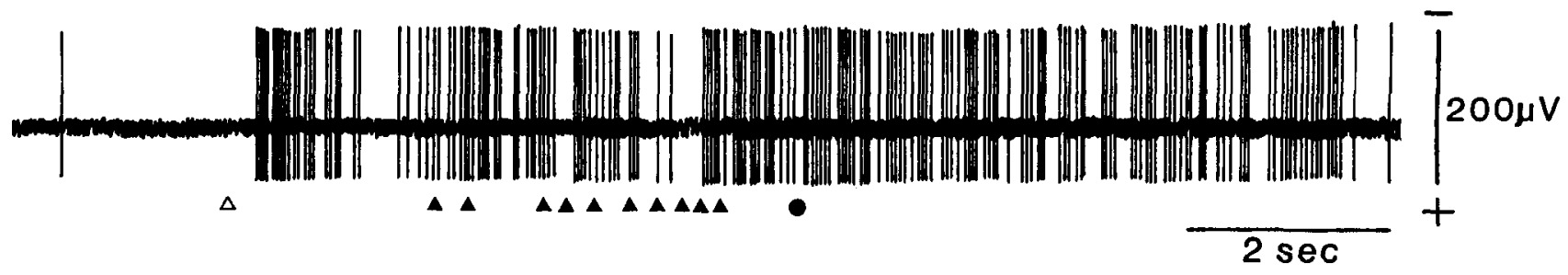

Figure 8. Responses of neuron selective to watermelon. A, Comparison of responses to various objects. Solid circles connected by heavy lines indicate mean firing rate in each trial for $5 \mathrm{sec}$ after W1 was opened in 3 repeated trials. Each histogram shows mean of each 5 sec mean firing rate after the indicated objects were revealed. Note pronounced response to watermelon. $B$, Raw record example of response to watermelon in one trial. Note pronounced responses to both sight and ingestion of watermelon. Other descriptions as for Figure 7.

reticular formation modulates sensory responses of the AM neurons (Sawa and Delgado, 1963), these discrepancies might be due to differences in experimental condition among these studies. In 3 cat studies, the animals were pharmacologically immobilized (Machne and Segundo, 1956; Creutzfeldt et al., 1963; Ben-Ari ct al., 1974), and in a fourth, the cat was frecly behaving (Sawa and Delgado, 1963). In the present study, the monkey's head was restrained, but it was free to respond and was well trained.

The AM is the one area that receives multimodal afferent information (Gloor, 1960; Turner et al., 1980). The multimodal neurons might be related to cross-modal association as suggested before (Ben-Ari and La Salle, 1972). The bilateral lesion of the monkey AM produced deficits in learning of cross-modal association (Murray and Mishkin, 1985).

\section{Selective neurons}

Fourteen neurons responded selectively to certain specific objects or sounds. Highly selective responses from neurons in the AM have been reported previously (O'Keefe and Bouma, 1969; Jacobs and McGinty, 1972). In the present study, neurons with this characteristic had extremely low spontaneous firing rates, which also agrees with the earlier reports (O'Keefe and Bouma,
1969; Jacobs and McGinty, 1972). Recently, Rolls (1984) reported that somewhat less than $3.6 \%$ of AM neurons were selective for faces. These neurons were located primarily in the basal and basal accessory nuclei. The selective neurons observed in the present study had a similar distribution. Richardson and Thompson (1984) reported that 2 ncurons out of 99 recorded in the AM responded uniquely to a cue tone when it was associated with the unconditioned stimulus.

Similar selective neurons have been reported in the inferotemporal cortex that responded to only one visual pattern--such as hand, face, and triangle-regardless of size or color (Gross et al., 1969, 1972; Sato et al., 1980; Desimone et al., 1984). Since the AM receives massive afferent projections from the inferotemporal cortex (Herzog and Van Hoesen, 1976; Aggleton et al., 1980; Turner et al., 1980; Iwai and Yukie, 1987), AM selective neurons might receive specific visual information from the inferotemporal cortex. There are important differences, however, between responses of AM and inferotemporal cortex selective neurons. AM selective neurons responded to multimodal stimulation (i.e., the sight and ingestion of a specific food item), while inferotemporal cortical neurons responded only to visual stimulation (Gross et al., 1972; Sato et al., 1980; Desimone et al., 1984). Thus, the pattern of responses in the AM suggests 

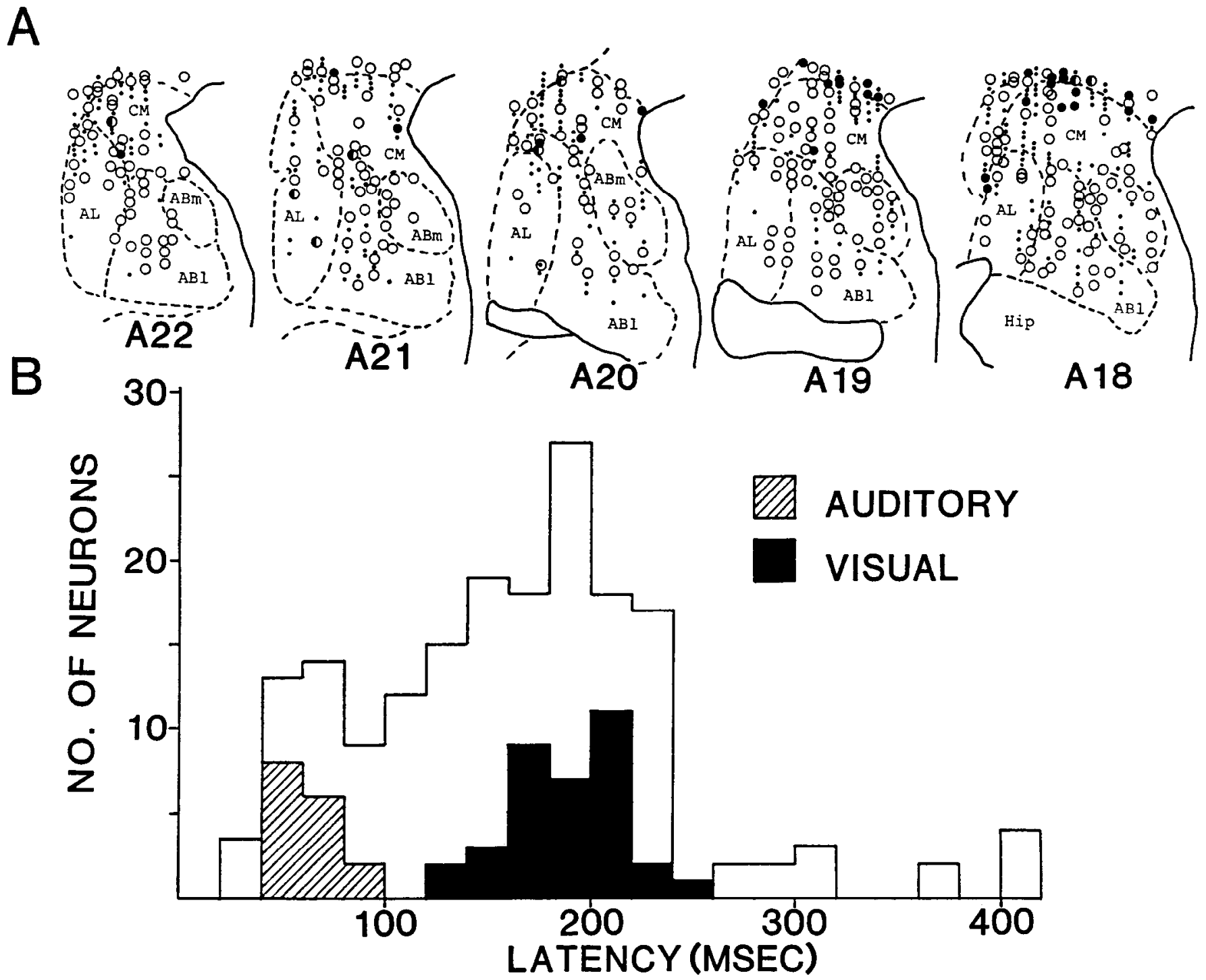

Figure 9. Recording sites and latencies of all the neurons analyzed. $A$, Recording sites with excitation-inhibition indicated: open circles, excitation; half-filled circles, excitation after inhibition; filled circles, inhibition; dots, no response. $C M$, Corticomedial group of amygdala (AM); $A L$, lateral nucleus; $A B l$, basolateral nucleus; $A B m$, basomedial nucleus. Numbers below each section indicate distance (mm) anterior from the interaural line. $B$, Histogram of response latency in routine tests. Open area, Latency of all neurons analyzed $(179.0 \pm 87.5 \mathrm{msec}, n=182)$; black area, latency of vision-rclatcd ncurons $(203.3 \pm 27.1 \mathrm{mscc}, n=35)$; hatched area, latency of audition-rclated ncurons $(78.1 \pm 13.8 \mathrm{msec}, n=16)$. Latency of visual responses obviously longer than latency of auditory responses (2-tailed Student's $i$ test, $p<0.001$ ).

convergence of specific sensory information from several modalities into single neurons in the AM. So they might be involved in object discrimination related to cross-modal association. The deficit in cross-modal association, especially in visual-gustatory association, is suggested to be one of the major causes of KlüverBucy syndrome (Klüver and Bucy, 1939) with visual agnosia (Geschwind, 1965).

\section{Topographic distribution of each type neuron}

The density of multimodal responses was rather uniform throughout the AM except in the lateral nucleus, where such responses were concentrated on the medial boundary. These results are consistent with studies in which central nucleus neurons in the rabbit were reported to respond to auditory, visual, and somesthetic stimuli (Pascoe and Kapp, 1985) and the basolateral group (Machne and Segundo, 1956) or central nucleus (Creutzfeldt et al., 1963) in cat responded to multimodal stimuli.
We further verified the existence of neurons that responded preferentially to single sensory modalities. Golgi studics suggest that the basolateral and lateral nuclei contain some small cells with dendritic fields confined to limited sensory terminal areas (Millhouse and de Olmos, 1983). Vision-related neurons were located primarily in the anterior dorsolateral AM. This is consistent with anatomical studies suggesting that visual afferents from the inferotemporal cortex terminate in the anterodorsal capsule of the basolateral group (Turner et al., 1980). Auditionrelated neurons were concentrated in the more posterior part of the basolateral group, where auditory afferents from the superior temporal gyrus terminate (Turner et al., 1980). In agreement with anatomical results (Turner et al., 1980), ingestion-related neurons were located in the corticomedial group and around the medial site of the lateral nucleus and along the dorsomedial border of the basolateral nucleus. Although anatomical evidence in monkey is lacking, in the rat the central nucleus in the cor- 


\section{A. VISION ( $)$; AUDITION (•); INGESTION (a)}
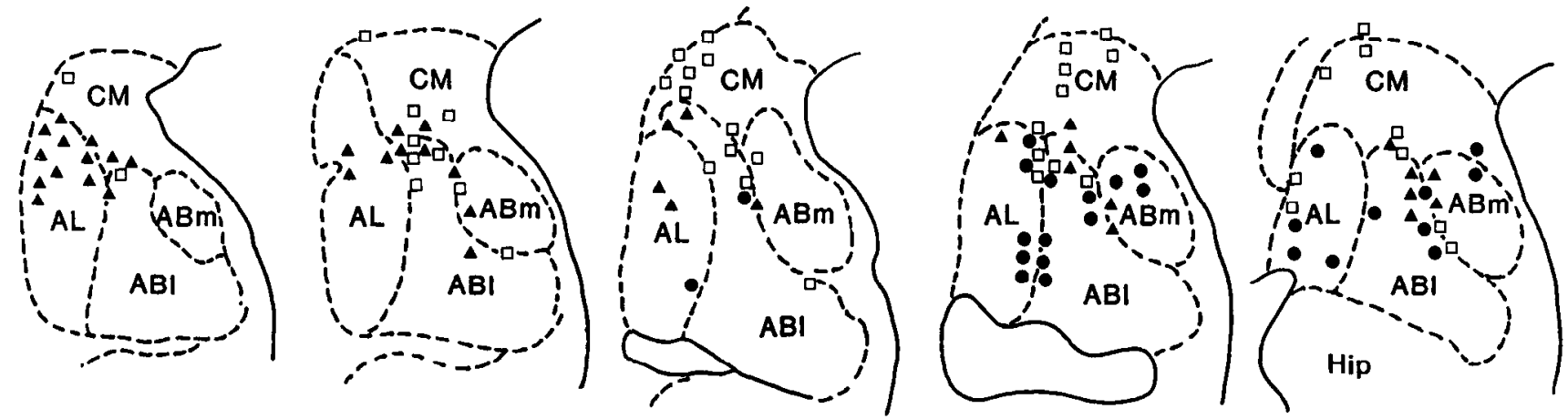

\section{B. MULTIMODAL PHASIC (0), TONIC ( $)$ : SELECTIVE (-)}
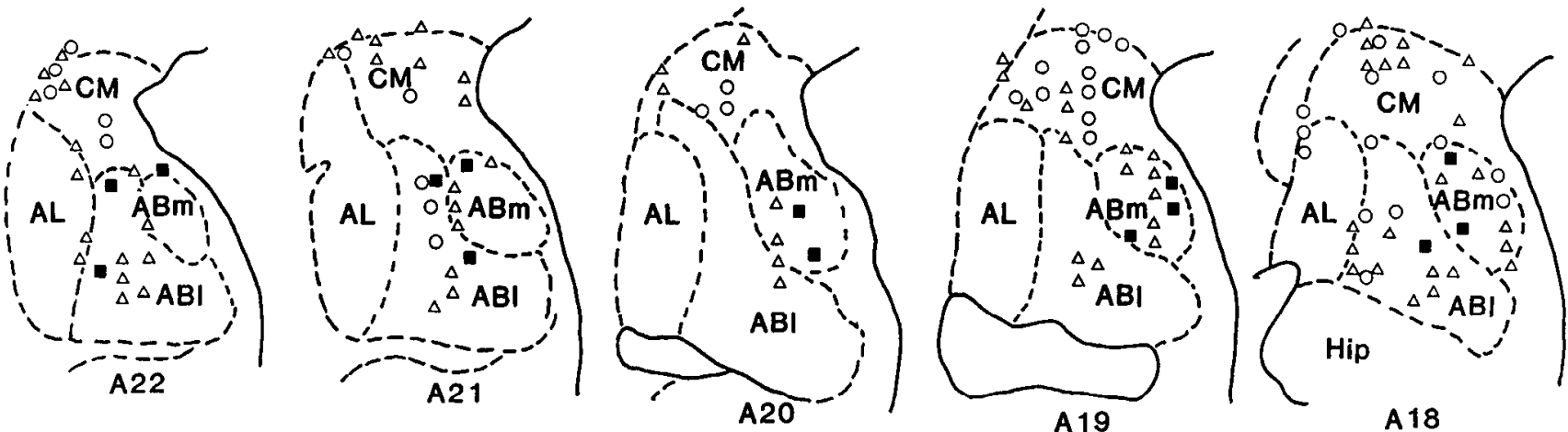

Figure 10. Recording sites of 5 major neuron types. A, Vision-related, flled triangles; audition-rclated, flled circles; ingestion-rclatcd, open squares. $B$, multimodal phasic, open circles; multimodal tonic, open triangles; selective, filled squares. Other details as for Figure $9 A$.

ticomedial group receives gustatory inputs from the parabrachial nucleus (Norgren, 1983).

\section{General discussion}

In our paradigm, AM neurons appeared to respond to 2 different dimensions of the stimuli: first, novelty-familiarity, with responses to novelty dominating; second, sensory specificity-generality, with multimodal responses most common, single modality next, and stimulus-specific responses least common. Lesions of the AM produce substantial behavioral deficits, particularly in acquisition of new information (Mishkin, 1978; ZolaMorgan et al., 1982; Duyckaerts et al., 1985) and in object recognition (Klüver-Bucy syndrome). The exact relationship between these behavioral deficits and the response characteristics of AM neurons remains unclear, both because the tasks used in the 2 types of experiments often differ and because, in both cases, the responses themselves are difficult to interpret. Nevertheless, the breadth of response characteristics and the specificity of many of the responses confirms that the AM has access to highly processed information from most or all sensory modalities.

\section{References}

Aggleton, J. P., and M. Mishkin (1984) Projections of the amygdala to the thalamus in the cynomolgus monkey. J. Comp. Neurol. 222: $56-68$.

Aggleton, J. P., and R. E. Passingham (1981) Stereotaxic surgery under $\mathrm{X}$-ray guidance in the rhesus monkey, with special reference to the amygdala. Exp. Brain Res. 44: 271-276.
Aggleton, J. P., M. J. Burton, and R. E. Passingham (1980) Cortical and subcortical afferents to the amygdala of the rhesus monkey ( $\mathrm{Ma}$ caca mulatta). Brain Res. 190: 347-368.

Albert, M. L., D. Soffer, R. Silverberg, and A. Reches (1979) The anatomic basis of visual agnosia. Neurology 29: 876-879.

Bagshaw, M. H., N. H. Mackworth, and K. H. Pribram (1972) The effect of resections of the inferotemporal cortex or the amygdala on visual orienting and habituation. Neuropsychologia 10: 153-162.

Ben-Ari, Y., and G. Le Gal La Salle (1972) Plasticity at unitary level. II. Modifications during sensory-sensory association procedures. Electroencephalogr. Clin. Neurophysiol. 32: 667-679.

Ben-Ari, Y., and G. Le Gal La Salle (1974) Lateral amygdala unit activity: II. Habituating and non-habituating neurons. Electroencephalogr. Clin. Neurol. 37: 463-472.

Ben-Ari, Y., G. Le Gal La Salle, and J. C. Champagnat (1974) Lateral amygdala unit activity: I. Relationship between spontaneous and evoked activity. Electroencephalogr. Clin. Neurophysiol. 37: 449461.

Creutzfeldt, O. D., F. R. Bell, and W. R. Adey (1963) The activity of neurons in the amygdala of the cat following afferent stimulation. Prog. Brain Res. 3: 31-49.

Crosby, E. C., and T. Humphrey (1941) Studies of the vertebrate telencephalon. II. The nuclear pattern of the anterior olfactory nucleus, tuberculum olfactorium and the amygdaloid complex in adult man. J. Comp. Neurol. 74: 309-352.

Desimone, R., T. D. Albright, C. G. Gross, and C. Bruce (1984) Stimulus-selective properties of inferior temporal neurons in the macaque. J. Neurosci. 4: 2051-2062.

Duyckaerts, C., C. Derouesne, J. L. Signoret, F. Gray, R. Escourolle, and P. Castaigne (1985) Bilateral and limited amygdalohippocampal lesions causing a pure amnesic syndrome. Ann. Neurol. 18:314-319.

Geschwind, N. (1965) Disconnexion syndromes in animals and man. Brain 88: 237-294.

Gloor, P. (1960) Amygdala. In Handbook of Physiology, Neurophys- 
iology. Vol. 2, J. Field, ed., pp. 1395-1420, American Physiological Society, Washington, D.C.

Gross, C. G., D. B. Bender, and C. E. Rocha-Miranda (1969) Visual receptive fields of neurons in inferotemporal cortex of the monkey. Science 166: 1303-1306.

Gross, C. G., C. E. Rocha-Miranda, and D. B. Bender (1972) Visual properties of neurons in inferotemporal cortex of the macaque. $J$. Neurophysiol. 35: 96-111.

Grossman, S. P. (1962) A Textbook of Physiological Psychology, Wiley, New York.

Herzog, A. G., and G. W. Van Hoesen (1976) Temporal neocortical afferent connections to the amygdala in the rhesus monkey. Brain Res. 115: 57-69.

Iwai, E., and M. Yukie (1987) Amygdalofugal and amygdalopetal connections with modality-specific visual cortical areas in macaques (Macaca fuscata, M. mulatta, and $M$. fascicularis). J. Comp. Neurol. 26I: 362-387.

Jacobs, B. L., and D. J. McGinty (1972) Participation of the amygdala in complex stimulus recognition and behavioral inhibition: Evidence from unit studies. Brain Res. 36: 431-436.

Johnston, J. B. (1923) Further contributions to the study of the evolution of the forebrain. J. Comp. Neurol. 35:337-481.

Kapp, B. S., R. C. Frysinger, M. Gallagher, and J. Haselton (1979) Amygdala central nucleus lesions: Effects on heart rate conditioning in the rabbit. Physiol. Behav. 23: 1109-1117.

Klüver, H., and P. C. Bucy (1939) Preliminary analysis of functions of the temporal lobes in monkeys. Arch. Neurol. Psychiatr. 42: 9791000 .

Kosar, E., H. J. Grill, and R. Norgren (1986a) Gustatory cortex in the rat. I. Physiological properties and cytoarchitecture. Brain Res. 379: 329-341.

Kosar, E., H. J. Grill, and R. Norgren (1986b) Gustatory cortex in the rat. II. Thalamocortical projections. Brain Res. 379: 342-352.

Kusama, T., and M. Mabuchi (1970) Stereotaxic Atlas of the Brain of Macaca fuscata. Tokyo University Press, Tokyo.

Machne, X., and J. P. Segundo (1956) Unitary responses to afferent volleys in amygdaloid complex. J. Neurophysiol. 19: 232-240.

Millhouse, O. E., and J. de Olmos (1983) Neuronal configurations in lateral and basolateral amygdala. Neuroscience 10: 1269-1300.

Mishkin, M. (1978) Memory in monkeys severely impaired by combined but not by separate removal of amygdala and hippocampus. Nature 273: 297-298.

Mishkin, M. (1982) A memory system in the monkey. Phil. Trans. R. Soc. London [Biol.] 298: 85-95

Murray, E. A., and M. Mishkin (1983) Severe tactual memory deficits in monkeys after combined removal of the amygdala and hippocampus. Brain Res. 270: 340-344.

Murray, E. A., and M. Mishkin (1985) Amygdalectomy impairs crossmodal association in monkeys. Science 228: 604-606.

Nakamura, K., and T. Ono (1986) Lateral hypothalamus neuron involvement in integration of natural and artificial rewards and cue signals. J. Neurophysiol. 55: 163-181.

Nakano, Y., L. Lenard, Y. Oomura, H. Nishino, S. Aou, and T. Yamamoto (1987) Functional involvement of catecholamines in reward related neuronal activity of the monkey amygdala. J. Neurophysiol. 57: 72-91.

Nishijo, H., T. Ono, K. Nakamura, M. Kawabata, and K. Yamatani (1986) Neuron activity in and adjacent to the dorsal amygdala of monkey during operant feeding behavior. Brain Res. Bull. 17: 847854.

Norgren, R. (1983) The gustatory system in mammals. Am. J. Otolaryngol. 4: 234-237.

O'Keefe, J., and H. Bouma (1969) Complex sensory propertics of certain amygdala units in the freely moving cat. Exp. Neurol. 23: 384398.
Ono, T., H. Nishino, K. Sasaki, M. Fukuda, and K. Muramoto (1980) Role of the lateral hypothalamus and the amygdala in feeding behavior. Brain Res. Bull. (Suppl. 4) 5: 143-149.

Ono, T., H. Nishino, K. Sasaki, M. Fukuda, and K. Muramoto (1981) Monkey lateral hypothalamic neuron response to sight of food, and during bar press and ingestion. Neurosci. Lett. 21: 99-104.

Ono, T., M. Fukuda, H. Nishino, K. Sasaki, and K. Muramoto (1983) Amygdaloid neuronal responses to complex visual stimuli in an operant feeding situation in the monkey. Brain Res. Bull. 11: 515-518.

Ono, T., K. Nakamura, H. Nishijo, and M. Fukuda (1986) Hypothalamic neuron involvement in integration of reward, aversion, and cue signals. J. Neurophysiol. 56: 63-79.

Pascoe, J. P., and B. S. Kapp (1985) Electrophysiological characteristics of amygdaloid central nucleus neurons in the awake rabbit. Brain Res. Bull. 14: 331-338.

Price, J. L. (1981) Toward a consistent terminology for the amygdaloid complex. In The Amygdaloid Complex, Y. Ben-Ari, ed., pp. 13-18, Elsevier/North Holland Biomedical, Amsterdam.

Pritchard, T. C., R. B. Hamilton, J. R. Morse, and R. Norgren (1986) Projection of thalamic gustatory and lingual areas in the monkey, Macaca fascicularis. J. Comp. Neurol. 244: 213-228.

Richardson, R. T., and R. F. Thompson (1984) Amygdaloid unit activity during classical conditioning of the nictitating membrane response in rabbit. Physiol. Behav. 32: 527-539.

Rolls, E. T. (1984) Neurons in the cortex of the temporal lobe and in the amygdala of the monkey with responses selective for faces. Human Neurobiol. 3: 209-222.

Ross, E. D. (1980) Sensory-specific and fractional disorders of recent memory in man. Arch. Neurol. 37: 193-200.

Sanghera, M. K., E. T. Rolls, and A. Roper-Hall (1979) Visual responses of neurons in the dorsolateral amygdala of the alert monkey. Exp. Neurol. 63: 610-626.

Sato, T., T. Kawamura, and E. Iwai (1980) Responsiveness of inferotemporal single units to visual pattern stimuli in monkeys performing discrimination. Exp. Brain Res. 38: 313-319.

Sawa, M., and J. M. R. Delgado (1963) Amygdala unitary activity in the unrestrained cat. Electroencephalogr. Clin. Neurophysiol. 15: 637650 .

Schwartzbaum, J. S., and J. R. Morse (1978) Taste responsivity of amygdaloid units in behaving rabbit: A methodological report. Brain Res. Bull. 3: 131-141.

Scott, T. R., S. Yaxley, Z. J. Sienkiewicz, and E. T. Rolls (1986) Gustatory responses in the frontal opercular cortex of the alert cynomolgus monkey. J. Neurophysiol. 56: 876-890.

Shipley, M. T., and Y. Geinisman (1984) Anatomical evidence for convergence of olfactory, gustatory, and visceral afferent pathways in mouse cerebral cortex. Brain Res. Bull. 12: 221-226.

Sudakov, K., P. D. MacLean, A. Reeves, and P. Marino (1971) Unit study of exteroceptive inputs to claustrocortex in awake, sitting, squirrel monkey. Brain Res. 28: 19-34.

Turner, B. H., M. Mishkin, and M. Knapp (1980) Organization of the amygdalopetal projections from modality-specific cortical association areas in the monkey. J. Comp. Neurol. 191: 515-543.

Yamamoto, T., S. Azuma, and Y. Kawamura (1981) Significance of cortical-amygdalar-hypothalamic connections in retention of conditioned taste aversion in rats. Exp. Neurol. 74: 758-768.

Yamamoto, T., N. Yuyama, T. Kato, and Y. Kawamura (1984) Gustatory responses of cortical neurons in rats. I. Response characteristics. J. Neurophysiol. 51: 616-635.

Zola-Morgan, S., L. R. Squire, and M. Mishkin (1982) The neuroanatomy of amnesia: Amygdala-hippocampus versus temporal stem. Science 218: 1337-1339. 